\title{
Overcoming ego-depletion: The influence of exemplar priming on self-control performance
}

Citation for published version (APA):

Martijn, C., Alberts, H. J. E. M., Merckelbach, H., Havermans, R. C., Huijts, A., \& de Vries, N. K. (2007). Overcoming ego-depletion: The influence of exemplar priming on self-control performance. European Journal of Social Psychology, 37, 231-238. https://doi.org/10.1002/ejsp.350

Document status and date:

Published: 01/01/2007

DOI:

10.1002/ejsp.350

Document Version:

Publisher's PDF, also known as Version of record

Document license:

Taverne

Please check the document version of this publication:

- A submitted manuscript is the version of the article upon submission and before peer-review. There can be important differences between the submitted version and the official published version of record.

People interested in the research are advised to contact the author for the final version of the publication, or visit the DOI to the publisher's website.

- The final author version and the galley proof are versions of the publication after peer review.

- The final published version features the final layout of the paper including the volume, issue and page numbers.

Link to publication

\footnotetext{
General rights rights.

- You may freely distribute the URL identifying the publication in the public portal. please follow below link for the End User Agreement:

www.umlib.nl/taverne-license

Take down policy

If you believe that this document breaches copyright please contact us at:

repository@maastrichtuniversity.nl

providing details and we will investigate your claim.
}

Copyright and moral rights for the publications made accessible in the public portal are retained by the authors and/or other copyright owners and it is a condition of accessing publications that users recognise and abide by the legal requirements associated with these

- Users may download and print one copy of any publication from the public portal for the purpose of private study or research.

- You may not further distribute the material or use it for any profit-making activity or commercial gain

If the publication is distributed under the terms of Article $25 \mathrm{fa}$ of the Dutch Copyright Act, indicated by the "Taverne" license above, 


\title{
Overcoming ego depletion: The influence of exemplar priming on self-control performance
}

\author{
CAROLIEN MARTIJN ${ }^{1 *}$, HUGO J. E. M. \\ ALBERTS ${ }^{1}$, HARALD MERCKELBACH ${ }^{1}$, \\ REMCO HAVERMANS ${ }^{1}$, ANNEMIEK HUIJTS ${ }^{1}$ \\ AND NANNE K. DE VRIES ${ }^{2}$ \\ ${ }^{1}$ Department of Experimental Psychology, \\ Universiteit Maastricht, Maastricht, \\ The Netherlands \\ ${ }^{2}$ Department of Health Education and Promotion, \\ Universiteit Maastricht, Maastricht, \\ The Netherlands
}

\begin{abstract}
Self-regulation research suggested that active self-control depends on a limited resource. Therefore the capacity for self-control is lower among people who already exercised control, a phenomenon labelled as ego depletion. This experiment examines whether priming of a persistent person exemplar may help to overcome ego depletion. Half of the participants engaged in a demanding self-control task (solving extremely difficult labyrinths) whereas the other half took part in a task that demanded little self-control (solving easy labyrinths). Then, half of the participants received a person exemplar prime related to persistence; the other half received a neutral prime. Finally, participants' persistence on a subsequent self-control task (squeezing a handgrip) was measured. The effect of a person exemplar prime on a subsequent self-control task depended on initial self-control demands. Participants who exercised high initial self-control and were then presented with a persistent exemplar prime showed assimilation. Their handgrip persistence was higher than the persistence of participants who received a neutral prime. Under conditions of low initial self-control the opposite pattern was found. A persistent person prime resulted in contrast and resulted in lower handgrip performance as compared to those who received a neutral prime. Copyright (C) 2006 John Wiley \& Sons, Ltd.
\end{abstract}

People often fail to control themselves successfully when they repeatedly exert self-control within a relatively short period of time. For example, a person who quits smoking and adopts a rigid regime in

\footnotetext{
*Correspondence to: C. Martijn, Universiteit Maastricht, Faculty of Psychology, Department of Experimental Psychology, PO Box 616, 6200 MD Maastricht, The Netherlands. E-mail: c.martijn@psychology.unimaas.nl

Contract/grant sponsor: The Netherlands Organization for Scientific Research (NWO); contract/grant number: 402-01-049.
}

Copyright (C) 2006 John Wiley \& Sons, Ltd.

Received 8 December 2004

Accepted 20 February 2006 
the same week will probably not achieve his or her goal of becoming a non-smoker in a slim body. Failure of subsequent acts of self-control is often explained in terms of limited self-regulatory strength (Baumeister, Heatherton, \& Tice, 1994; Baumeister \& Heatherton, 1996; Baumeister, Bratslavsky, Muraven, \& Tice, 1998). By this view, controlling oneself consumes strength or energy of some central, limited resource. After an act of self-control, the resource is temporarily exhausted, leaving the individual in a state of ego depletion. Therefore, a following self-control activity is likely to fail. According to the limited strength model, self-control operates like a muscle; strong at first, but weak and tired after use. Further, the model assumes that people tend to conserve their strength when resources are low (Baumeister, Muraven, \& Tice, 2000, p. 139).

To date, the research programme of Baumeister, Muraven and their colleagues identified a variety of self-control behaviour that seems to depend on strength and, hence, result in ego depletion. It was shown that virtually all non-habitual behaviours that require active involvement of the self's executive functions draw on strength. Inhibiting impulses, altering emotions, active choice making, suppressing forbidden thoughts, executing complex cognitive tasks and persisting in aversive tasks are examples of such active, self-operations and likely to impact negatively on subsequent self-control attempts (see for overviews Muraven \& Baumeister, 2000; Schmeichel \& Baumeister, 2004). In the light of this evidence an important question is then whether the negative effects of strength depletion can be counteracted in order to improve people's chances to realise their goals. Only a few studies specifically tested ways to improve self-regulatory strength. In one of these studies, Muraven, Baumeister, and Tice (1999) tested their reasoning that if self-control resembles strength, repeated exercise of strength should result in increasing resources. Students who engaged in a 2-week period of 'ego-control training' (such as keeping food diaries or improving posture) performed better on a physical self-control measurement than a non training control group. Other studies demonstrated that ego depletion may be compensated by changing people's expectancies related to self-control or by increasing people's motivation to perform well on a subsequent control task (Martijn, Tenbült, Merckelbach, Dreezens, \& De Vries, 2002; Muraven \& Slessareva, 2003).

In this present article, we will examine whether a less intensive intervention may also work to enhance maintenance of control behaviour. More precisely, we will examine whether priming concepts such as persistence, perseverance and determination prevents loss of self-control. But why would a relatively simple intervention such as priming work? Our reasoning for this assumption was as follows. As described by Baumeister et al. (2000; see also Schmeichel \& Baumeister, 2004, p. 87), ego depletion should be understood as the tendency to conserve the energy that is still left and not as a sign of complete exhaustion. These authors do not specify whether strength conservation reflects a conscious and deliberate decision or a more or less automatic tendency of which people are not necessarily aware of. In our view, the second view is most likely to be true. The tendency to conserve resources should probably be interpreted as a standard or default reaction. After exertion of strength, people switch to a standby mode and do not spend more energy than strictly necessary. When individuals tend to react on further self-control demands in a low profile, standby sort of way, the question then is whether they may be switched back to full operation mode again, and if so, by what means. Previous research of Webb and Sheeran (2003) provided preliminary evidence that automation procedures such as forming implementation intentions prompted participants to overcome ego depletion. In similar vein, increasing the accessibility of behaviour that is closely associated with self-control may also offset the effects of ego depletion. Priming of such behaviour could produce automatic pursue of self-control and thus circumvents the need for active and conscious self-regulation. Precisely because of the absence of such need, this may be in particular useful for individuals who already suffer from resource depletion.

In the present study, we examined whether priming participants with a highly persistent person exemplar enabled them to overcome ego depletion. Does the presentation of a persistent exemplar in an ostensibly unrelated task evoke maintenance of self-control, especially under conditions of ego 
depletion? To study this, all participants performed the same sequence of tasks. The first part of the study consisted of the manipulation of self-control. Participants were presented with a large series of moderately easy labyrinths or a series of extremely difficult labyrinths. The labyrinths were selected on the basis of a pilot study in which the difficult labyrinths, as compared to the more easy ones, were judged as almost impossible to solve. Pilot participants indicated that trying to solve difficult labyrinths was exacting and that they had to force themselves to continue after a few minutes. In the second part of the study, participants took part in a supposedly unrelated study in which they had to read a text. Half of the participants received a text that described a person exemplar demonstrating perseverance and motivation. The other half of the participants received a neutral text. The third part consisted of a physical stamina task that was adapted from Muraven, Tice, and Baumeister (1998) and consisted of squeezing a handgrip. Although squeezing a handgrip seems primarily a matter of muscular strength, it has proved a successful measure of self-control in prior research (see for example Muraven et al., Exp. 1; Ciarocco, Sommer, \& Baumeister, 2001, Exp. 2). Squeezing a handgrip becomes fatiguing after a short period of time and the person feels the urge to stop. Overcoming this fatigue and overriding the urge to quit, requires selfcontrol. We adopted the physical stamina measure as main dependent variable because of two reasons. First, because most people think that a handgrip primarily depends on muscular strength it is a relatively unobtrusive measure for self-control. Second, because squeezing a handgrip was quite distinct from the other tasks we used in this experiment to induce depletion and to prime perseverance, participants were less likely to suspect any relation between the tasks. To control for individual differences, handgrip performance was measured twice: before the labyrinth task and after reading the text. ${ }^{1}$

Our first prediction was that under neutral conditions of priming, participants who took part in an initial high self-control task (difficult labyrinths) will lower their performance on the second handgrip measure as compared to participants who took part in an initial low self-control task (easy labyrinths). In other words, we expected to replicate the basic pattern of ego depletion.

Our second prediction was that exemplar priming of persistence would produce different effects for non-depleted and depleted participants. We expected non-depleted participants to lower their performance on the second handgrip task. As demonstrated by Dijksterhuis et al. (1998), priming with an exemplar will under normal circumstances lead to contrast. Because non-depleted participants will involve in social comparison between themselves and the persistent Olympic champion they are likely to conclude that they are relatively weak-willed. Such self-related activation of weakness of will may well cause them to perform less well on a subsequent self-control task. We expected an assimilation effect for depleted participants, as reflected in stable performance at the second handgrip measurement. Because depleted participants are low in resources, they will not engage in thorough processing of the appropriateness of a prime in terms of its comparison relevance. Therefore the activation of perseverance and determination will incite them to keep on going at the following physical self-control task.

\section{METHOD}

\section{Participants and Design}

Seventy-seven undergraduate students (59 women) of the University of Maastricht were randomly assigned to the conditions of a 2 (Self-control: low vs. high) $\times 2$ (Type of Prime: neutral vs.

\footnotetext{
${ }^{1}$ Because of the base line measurement of physical stamina, all participants started the experiment with a self-control task and thus exercised some self-control before they were subjected to the actual manipulation of self-control (solving easy vs. difficult labyrinths). Therefore, it is actually more exact to say that our comparison was between low depleted versus high depleted participants instead of non-depleted versus depleted participants. However, for the sake of clarity we will follow the terminology of prior studies that used similar paradigms and refer to the labyrinth task as initial self-control.
} 
perseverance) design. The main dependent variable was the difference in handgrip performance on the pre-test and the post-test, i.e. decline in self-control performance. The experiment was approved by the standing ethical committee of the Faculty of Psychology.

\section{Procedure}

All participants were individually tested in 45 minutes sessions. The experiment was presented as a series of unrelated cognitive and physical exercise tasks. The experimenter briefly explained the content of the tasks, after which participants signed a consent form. Next, the experimenter asked participants to place a handgrip in their dominant hand and inserted a matchstick between the two handles as soon as the participant squeezed them together. The moment that the participant relaxed his or her grip, the match fell out. The experimenter started a stopwatch at the moment she placed a match between the handles and stopped timing when the match fell out (procedure adapted from Muraven et al., 1998, p. 177). After the first handgrip task, participants received a series of relatively easy labyrinths (low self-control) or a series of extremely difficult labyrinths (high self-control). Participants were instructed to solve as many of the labyrinths as they could within 10 minutes. Subsequently, participants were informed that they would now take part in another study on text reading and interpretation. In fact, the text reading task consisted of our priming manipulation. Half of the participants were presented with a text about a person exemplar who represented perseverance. A text was composed about the Dutch ice-skater Gerard Van Velde who, after serious setbacks and disappointments, won the 1000 metre race at the Olympic Winter Games in Salt Lake City in a new world record. We combined excerpts of newspaper articles that portrayed Van Velde as a typical, but sympathetic, 'go-getter'. The text described that Van Velde finished fourth at the 500 metre, missing a medal by 0.02 seconds. However, at the 1000 metre he skated his best race ever because 'I gave it my best shot when I was out there. I kept telling myself: don't give up, don't quit. At a certain moment I thought, I gave it all. Strange enough, you can do more than you think. I have learnt that I can do much more than I thought: you have to go for it'. To hide the true purpose of the text, i.e. priming perseverance, the text was presented as a cognitive task. Participants had to detect five words that did not fit in the context.

In the neutral prime condition, a text was presented about the International Olympic Committee (IOC) in which participants had to detect the same five out-of-context words. The texts were about equally long (Van Velde: 511 words, IOC: 498 words). After reading the text, participants squeezed the handgrip for the second time, using the same procedure as for the first handgrip measurement. Exit interviews held before debriefing indicated that no participant recognised the true purpose of the experiment.

\section{Physical Self-Control Performance}

To control for individual differences, physical self-control performance was measured twice: at the beginning of the experiment and after the priming manipulation. Using a stopwatch, the time (in milliseconds) was measured that a participant squeezed the handles of a handgrip together.

\section{RESULTS}

For each participant the difference score between the first and the second handgrip was calculated. Four participants showed deviant differences scores $(z>3)$ and were recognised as outliers. Their data 
was omitted, leaving 73 participants for further analysis. First, we inspected whether the four conditions did not differ with respect to initial handgrip strength. A one-way analysis of variance with pre-test handgrip times and the four conditions as independent variable, showed a non-significant difference, $F(3,69)=2.18, p=11$. Next, the effectiveness of our ego depletion manipulation was checked. Within the neutral prime condition, we compared the difference between the pre-test and post-test of handgrip endurance of high self-control and low-self-control participants. The mean difference between pre-test and post-test handgrip times of participants who solved difficult labyrinths (high self-control) was -128 milliseconds ( $S D$ 1673), the mean difference of participants who solved easy labyrinths (low self-control) was -1374 milliseconds (SD 1946). This difference was significant, $F(1,35)=4.20, p=0.048$, and was interpreted as an indication of the effectiveness of our ego depletion manipulation. Our main analysis consisted of a 2 (Self-control: easy vs. difficult labyrinths) $\times 2$ (Type of Prime: neutral vs. perseverance) analysis of variance in which difference score between the pre- and post handgrip measurement were entered. Main effects of self-control and priming were non-significant $(F$ 's $<1)$ and were fully qualified by the two-way interaction of selfcontrol and priming, $F(1,69)=6.97, p<0.01$ (see Figure 1). An alternative ANCOVA on the posttest scores, using the pre-test scores as an covariate, yielded the same significant interaction between self-control and type of prime, $F(1,68)=2.17, p<0.05$. To examine the two-way interaction, we continued with planned comparisons. Within the low self-control condition, the difference in handgrip times of neutrally primed participants was smaller than that of participants primed with persistence, $t$ $(69)=1.98, p$ two-tailed $=0.04$. This indicated that participants who exercised low self-control, maintained their handgrip at the same level after reading a neutral text, and lost their grip after reading about a persistent exemplar. Within the high self-control condition, the reverse pattern emerged: differences in handgrip times of neutrally primed participants were higher than participants primed with persistence, $t(69)=2.26, p$ two-tailed $=0.03$. Thus, under conditions of high initial self-control,

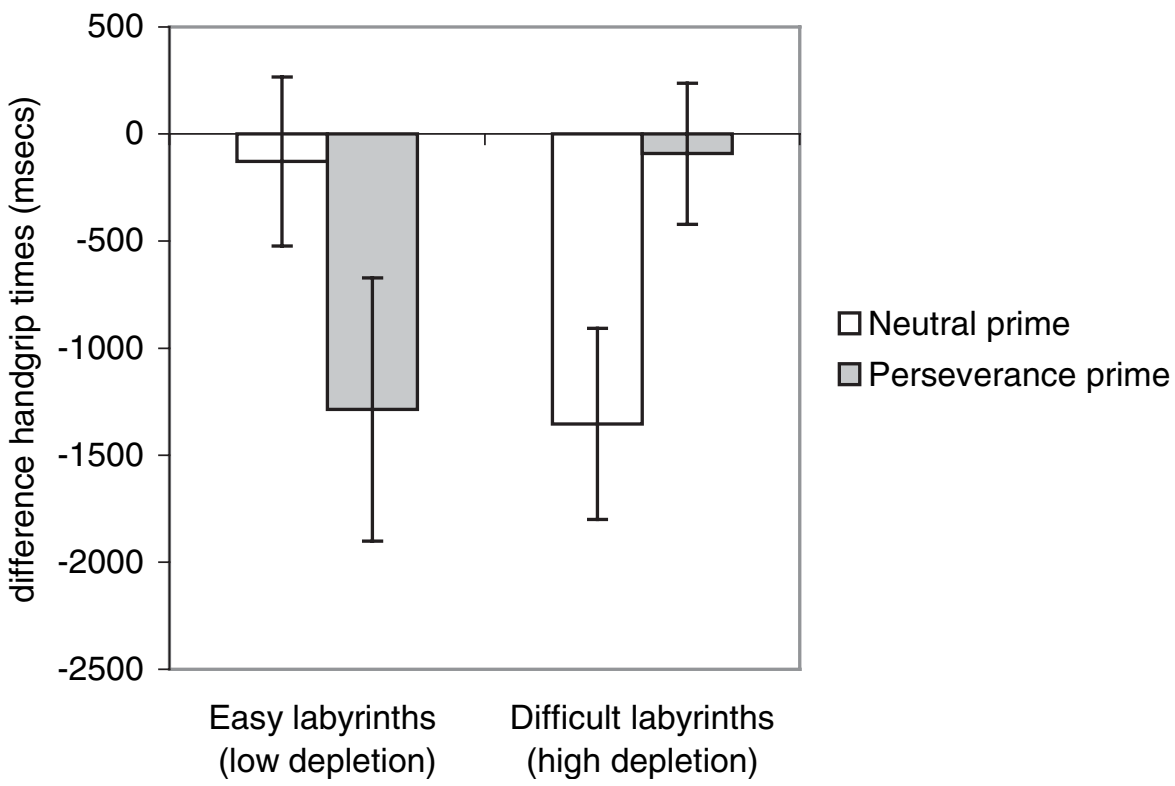

Figure 1. Mean difference $( \pm 1 S E)$ of the two handgrip measurements as a function of initial self-control and type of priming 
persistence primed participants maintained their grip whereas neutrally primed participants showed lowered handgrip times. ${ }^{2}$

\section{DISCUSSION}

This study tested whether priming may counteract the negative effects of ego depletion. Participants took part in a task that appealed either high or low on their self-control (difficult versus easy labyrinths) and then performed a second physical self-control task (squeezing a handgrip) which was compared to a base-line measurement. In between the manipulation of initial self-control (labyrinths) and assessment of physical self-control (handgrip), half of the participants were primed with persistence by reading a text about a perseverant Olympic ice-skater. The other half read a neutral a text that was unrelated to persistence.

Participants who received a persistence-related exemplar prime after exercising high self-control, maintained their grip on the following physical self-control task. High self-control participants, who were exposed to a neutral prime, lowered their performance on the physical self-control task. Under conditions of low self-control, the reverse pattern was found. In this case, persistence-related exemplar priming resulted in lower performance at the second handgrip measurement whereas neutral priming resulted in a performance equal to base line. Taken together then, we have demonstrated that the effect of a persistence-related exemplar depends on depletion status. A persistent exemplar evokes assimilation when participants are relatively fatigued or depleted, and leads to contrast when participants are relatively fit or non-depleted.

Our results are consistent with those of earlier studies in which was demonstrated that person exemplars effect in contrast (Dijksterhuis et al., 1998; Stapel, Koomen, \& Van der Pligt, 1997). According to Dijksterhuis et al., (1998, p. 869) concrete person exemplars elicit social comparison of the exemplar with the self. However, because person exemplars are narrow and distinct priming stimuli, they are likely to be excluded from the self and to produce contrast. This is especially likely when such primes represent an extreme example of certain traits or behaviour (Stapel et al., 1997). In our study, the well-known Dutch Olympic ice-skater should be considered as a rather extreme person exemplar who therefore elicited social comparison. As compared to the persistent Olympic ice-skater, participants were likely draw a negative conclusion with respect to their own persistence. Thus, the persistent exemplar may have led to an association between their own self-concept and (relatively) low persistence which was reflected in lower performance on the following physical self-control task.

The question then is why depleted participants showed assimilation. A plausible explanation is that it requires some effort to detect (dis)similarities between oneself and the exemplar and to correct one's self-concept. Because depleted persons lack such resources (or tend to conserve what is left), they processed the exemplar prime less intensively than their non-depleted counterparts. Depleted participants probably simply followed the 'persistence' and 'perseverance' cues activated by the exemplar and did not acknowledge or correct for the difference between the exemplar and themselves. This explanation is consistent with Gilbert's argument that acceptance is part of comprehension whereas rejection occurs subsequent and requires more effort (Gilbert, 1991). People first accept what they see, hear and read, and analyse, question, scrutinise their initial beliefs not until later. When resources are low, people tend to accept information because they lack the energy necessary for careful

\footnotetext{
${ }^{2}$ After finishing the easy or difficult labyrinths, all participants filled out the Brief Mood Inspection scale (BMIS, Mayer \& Gaschke, 1988). For each participant, we computed the mean BMIS score to obtain a mood score $(\alpha=0.82)$. Analyses indicated that there was no mood difference between participants who tried to solve easy or difficult labyrinths, $t(1,71)=0.92, p=0.36$.
} 
scrutiny and subsequent rejection (e.g. Gilbert, Pelham, \& Krull, 1988; Petty \& Cacioppo, 1986). As Gilbert (1991, p. 111) argues, resource depletion facilitates believing and persuasion.

Taken together, this leads to an almost paradoxical conclusion. Persistent, strong-willed exemplars may facilitate future self-control but only if people are low in resources because of recently exercised strength. When tired and exhausted, people tend to assimilate to the characteristics and behaviour of an exemplar, in spite of his extremity ("if he can do it, then I can too'). The effect of persistent exemplars hinders future control under conditions of non depletion because then people detect and correct for the extremity of an exemplar. When fit and fresh, people show contrast ('I am not such a go-getter as the ice-skater').

Conclusively, our results form a first empirical demonstration of how the negative effects of ego depletion may be prevented by a relatively simply priming procedure. To gain more insight in the underlying mechanism of this effect, future research may address the question whether priming fully counteracts ego depletion or only delays its consequences. For example, what would happen if participants primed with persistence who performed well on a subsequent self-control task, were asked to exercise control again? If priming encourages people to spend the left-over energy they normally tend to spare, then the negative effects of ego depletion should become apparent on a third control task. If priming is not associated with delayed loss of control, this would indicate that priming is capable to fully offset the effects of ego depletion. The latter outcome would suggest that if the mere thought of a persistent person results in continuous control, self-control performance may be less driven by energy than generally assumed.

\section{REFERENCES}

Baumeister, R. F., Bratslavsky, E., Muraven, M., \& Tice, D. M. (1998). Ego-depletion: Is the active self a limited resource? Journal of Personality and Social Psychology, 74, 1252-1265.

Baumeister, R. F., \& Heatherton, T. F. (1996). Self-regulation failure: An overview. Psychological Inquiry, 7, 1-15.

Baumeister, R. F., Heatherton, T. F., \& Tice, D. M. (1994). Losing control: How and why people fail at selfregulation. San Diego, CA: Academic Press.

Baumeister, R. F., Muraven, M., \& Tice, D. M. (2000). Ego-depletion: A resource model of volition, self-regulation and controlled processing. Social Cognition, 18, 130-150.

Ciarocco, N. J., \& Sommer, K. L., \& Baumeister, R. F. (2001). Ostracism and ego depletion: The strains of silence. Personality and Social Psychology Bulletin, 27, 1156-1163.

Dijksterhuis, A., Spears, R., Postmes, T., Stapel, D., Koomen, W., Van Knippenberg, A., \& Scheepers, D. (1998). Seeing one thing and doing another: Contrast effects in automatic behavior. Journal of Personality and Social Psychology, 75, 862-871.

Gilbert, D. T. (1991). How mental systems believe. American Psychologist, 46, 107-119.

Gilbert, D. T., Pelham, B. W., \& Krull, D. S. (1988). On cognitive busyness: When perceiver meets persons perceived. Journal of Personality and Social Psychology, 54, 733-740.

Martijn, C., Tenbült, P., Merckelbach, H., Dreezens, E., \& De Vries, N. K. (2002). Getting a grip on ourselves: Challenging expectancies about loss of energy after self-control. Social Cognition, 20, 441-458.

Mayer, J. D., \& Gaschke, Y. N. (1988). The experience and meta-experience of mood. Journal of Personality and Social Psychology, 55, 102-111.

Muraven, M., \& Baumeister, R. F. (2000). Self-regulation and depletion of limited resources: Does self-control resemble a muscle? Psychological Bulletin, 126, 247-259.

Muraven, M., Baumeister, R. F., \& Tice, D. M. (1999). Longitudinal improvement of self-regulation through practice: Building self-control strength through repeated exercise. Journal of Social Psychology, 139, 446-457.

Muraven, M., \& Slessareva, E. (2003). Mechanisms of self-control failure: Motivation and limited resources. Personality and Social Psychology Bulletin, 29, 894-906.

Muraven, M., Tice, D. M., \& Baumeister, R. F. (1998). Self-control as limited resource: Regulatory depletion patterns. Journal of Personality and Social Psychology, 74, 774-789. 
Petty, R. E., \& Cacioppo, J. T. (1986). The elaboration likelihood model of persuasion. In L. Berkowitz (Ed.), Advances in experimental psychology (Vol. 19, pp. 123-205). San Diego: CA: Academic Press.

Schmeichel, B. J., \& Baumeister, R. F. (2004). Self-regulatory strength. In R. F. Baumeister \& K. D. Vohs (Eds.), Handbook of self-regulation: Research, theory, and applications (pp. 84-98). New York: Guilford Press.

Stapel, D. A., Koomen, W., \& Van der Pligt, J. (1997). Categories of category accessibility: The impact of trait versus exemplar priming on person judgments, Journal of Experimental Social Psychology, 33, 44-76.

Webb, T. L., \& Sheeran, P. (2003). Can implementation intentions help to overcome ego-depletion? Journal of Experimental Social Psychology, 39, 279-286. 